\title{
OPEN Development of a new biocathode for a single enzyme biofuel cell fuelled by glucose
}

\author{
Asta Kausaite-Minkstimiene ${ }^{1 凶}$, Algimantas Kaminskas ${ }^{1}$, Anton Popov ${ }^{1}$, \\ Arunas Ramanavicius ${ }^{2}$ \& Almira Ramanaviciene ${ }^{1 \bowtie}$
}

In this study, we reported the development of Prussian blue (PB), poly(pyrrole-2-carboxylic acid) (PPCA), and glucose oxidase (GOX) biocomposite modified graphite rod (GR) electrode as a potential biocathode for single enzyme biofuel cell fuelled by glucose. In order to design the biocathode, the GR electrode was coated with a composite of PB particles embedded in the PPCA shell and an additional layer of PPCA by cyclic voltammetry. Meanwhile, GOx molecules were covalently attached to the carboxyl groups of PPCA by an amide bond. The optimal conditions for the biocathode preparation were elaborated experimentally. After optimization, the developed biocathode showed excellent electrocatalytic activity toward the reduction of $\mathrm{H}_{2} \mathrm{O}_{2}$ formed during $\mathrm{GOx}$ catalyzed glucose oxidation at a low potential of $0.1 \mathrm{~V}$ vs $\mathrm{Ag} / \mathrm{AgCl}$, as well as good electrochemical performance. An electrocatalytic current density of $31.68 \pm 2.70 \mu \mathrm{A} / \mathrm{cm}^{2}$ and open-circuit potential (OCP) of $293.34 \pm 15.70 \mathrm{mV}$ in $\mathrm{O}_{2}$-saturated $10 \mathrm{mM}$ glucose solution at $\mathrm{pH}$ 6.0 were recorded. A maximal OCP of $430.15 \pm 15.10 \mathrm{mV}$ was recorded at $98.86 \mathrm{mM}$ of glucose. In addition, the biocathode showed good operational stability, maintaining $95.53 \pm 0.15 \%$ of the initial response after 14 days. These results suggest that this simply designed biocathode can be applied to the construction of a glucose-powered single enzyme biofuel cell.

With the growing demand for green electrical energy generation technologies, scientists are making great efforts to develop fuel cells (FCs), which are considered as one of the most promising alternative sustainable energy sources due to their renewable and environmental protection characteristics ${ }^{1}$. Unlike conventional FCs, which utilize the oxidation of fuels $\left(\mathrm{H}_{2}\right.$, ethanol, or methanol) on an anode and reduction of an oxidant on a cathode employing a noble metal catalyst ${ }^{2}$, biological fuel cells (biofuel cells, BFCs) convert chemical energy into electrical energy by using organic fuels (sugars, alcohols, organic acids) produced during metabolic processes and a biological catalyst, which is usually either a microorganism or an enzyme. An enzymatic biofuel cells (EBFCs) are type of BFCs that use purified redox enzymes immobilized on an anode and/or on a cathode to achieve electrocatalytic reactions ${ }^{3}$. Enzymes are highly specific to their respective substrate and typically operates in mild conditions. Therefore, BFCs are an attractive alternative when it is not possible to use high temperatures or where harsh reaction conditions are undesirable. Moreover, enzymes immobilized on the electrode surface allow membrane-less configuration of EBFCs, opening up opportunities for the development of miniaturized systems for powering electronic devices ${ }^{4}$ and self-powered electrochemical biosensors, the main advantage of which is a simplified two-electrode system without an external power supply ${ }^{5}$. In addition to lactate ${ }^{6}$, cholesterol $^{7}$, ethanol ${ }^{8}$ and other EBFCs, special interest in recent years has been focused on the development of membrane-less EBFCs that can deliver electrical energy using oxidation of glucose at an anode and $\mathrm{O}_{2}{ }^{9,10}$ or $\mathrm{H}_{2} \mathrm{O}_{2}{ }^{11,12}$ reduction at a cathode. Glucose and $\mathrm{O}_{2}$ are an ideal source of fuel and oxidizer because they are found in all organic tissues and can be constantly replenished during metabolic processes ${ }^{13}$. EBFCs that use enzymatic reactions on both electrodes have also been researched and published ${ }^{14,15}$. Researchers expect that in the future, miniature membrane-less EBFCs will supply energy to implantable medical devices, like insulin pumps, hearing devices, bone stimulators or pacemakers, and will also be used as self-powered biosensors, which, using an analyte as a fuel, will be able to supply themselves with energy, and at the same time to determine the amount of an analyte ${ }^{16}$. Implanted self-powered biosensors could be used to measure various substances that cause heart disease or cancer, as well as blood glucose $\mathrm{e}^{17,18}$. To use EBFCs for these purposes, they should be small and light, operate at

\footnotetext{
${ }^{1}$ Nanotechnas - Center of Nanotechnology and Materials Science, Institute of Chemistry, Faculty of Chemistry and Geosciences, Vilnius University, Naugarduko st. 24, 03225 Vilnius, Lithuania. ${ }^{2}$ Department of Physical Chemistry, Institute of Chemistry, Faculty of Chemistry and Geosciences, Vilnius University, Naugarduko st. 24, 03225 Vilnius, Lithuania. ${ }^{\boxplus}$ email: asta.kausaite@chf.vu.It; almira.ramanaviciene@chf.vu.It
} 
body temperature, $\mathrm{pH}$, and salt concentration, as well as be able to generate a sufficient amount of energy and have good operational stability. Due to insufficient power output, voltage output, and operational stability, the development of high-performance EBFCs is still required.

Over the last decade, the performance of EBFCs has greatly improved by using various nanomaterials, such as carbon nanotubes (CNTs), graphene oxide (GO), noble metal nanoparticles or conjugated polymers (CPs). These materials often have good biocompatibility, also electrical conductivity and large surface area. Their use allows to improve the efficiency of electron transfer and a magnitude of the generated electrical signal and often provides a stable matrix for enzyme immobilization. Due to the large surface area, nanomaterials can increase enzyme loading, furthermore, to improve the activity and stability of immobilized enzymes, thus improving the performance of EBFCs. Among the nanomaterials mentioned, CPs and CPs-based nanocomposites have gained the considerable attention of many scientists. For example, Haque and co-workers ${ }^{19}$ reported a glassy carbon electrode modified with a conducting composite consisting of chitosan, reduced GO, polyaniline (PANI), ferritin and glucose oxidase $(\mathrm{GOx})$ as a potential bioanode for glucose EBFC. The bioanode was capable to generate a current of $3.5 \mathrm{~mA} / \mathrm{cm}^{2}$ at $20 \mathrm{mM}$ of glucose. The performance was improved due to the porosity and large surface area of the composite material, which allows the immobilization of a larger amount of enzyme and facilitates the diffusion of glucose. Although the bioanode generated a lower current signal, it nevertheless had a high operational stability and maintained $95 \%$ of the initial response after one week. Kang and co-workers ${ }^{20}$ proposed a glucose $/ \mathrm{O}_{2}$ EBFC based on glassy carbon electrodes modified with a novel three-dimensional PANI and CNTs composite with rhizobium-like structure. The composite was prepared by in-situ polymerization of aniline monomers around and along the functionalized CNTs and then carbonized at a high temperature was used as a substrate for immobilization of GOx (anode) and laccase (Lac) (cathode). The EBFC was performed with a maximum power density of $1.12 \mathrm{~mW} / \mathrm{cm}^{2}$ at $0.45 \mathrm{~V}$. Moreover, three fabricated EBFCs connected in series were able to light up a yellow light-emitting diode (LED) whose turn-on voltage was about at 1.8 V. Later Kang and co-workers ${ }^{21}$ reported glucose $/ \mathrm{O}_{2}$ EBFC based on GOx and Lac immobilized on carbonized rectangular polypyrrole tubes. A nickel foam was utilized as the substrate electrode. The open-circuit voltage The opencircuit of the designed EBFC reached $1.16 \mathrm{~V}$ and the maximum power density was measured to $0.350 \mathrm{~mW} / \mathrm{cm}^{2}$ at $0.85 \mathrm{~V}$. Three of the fabricated EBFCs connected in series were able to light up a white LED whose turn-on voltage was about at $2.4 \mathrm{~V}$ for more than $48 \mathrm{~h}$.

Most of the glucose EBFCs utilize glucose-oxidizing enzyme (GOx or glucose dehydrogenase) on a bioanode combined with oxygen reducing enzymes (commonly bilirubin oxidase or Lac) on a biocathode. Biocathodes based on immobilized peroxidase (PO) ${ }^{14,22}$ and biocathodes in which GOx is combined with PO that catalyses the reduction of $\mathrm{H}_{2} \mathrm{O}_{2}$, produced during glucose oxidation on GOx modified electrodes ${ }^{23}$, have also been published. Such systems have a drawback: the use of two enzymes, which makes the system more complex and increases the cost. In addition, enzymes used may have different optimal operating conditions. These drawbacks can be avoided by designing a so-called single enzyme EBFC, in which the same enzyme is used for the anodic and cathodic reactions. The present paper describes the fabrication and investigation of a novel biocathode in the construction of which an "artificial PO" Prussian blue (PB) was used instead of PO. According to the mechanism of $\mathrm{H}_{2} \mathrm{O}_{2}$ reduction on $\mathrm{PB}$ modified electrodes, $\mathrm{PB}$ is electrochemically reduced to form Prussian white (PW), which catalyses the reduction of $\mathrm{H}_{2} \mathrm{O}_{2}$ at low potential ${ }^{24}$ and $\mathrm{PW}$ is oxidized to $\mathrm{PB}$ again. Due to the reversible electrochemical redox ability of $\mathrm{PB}$, it acts as a renewable catalyst throughout the electrochemical process ${ }^{25}$. Although PO-like property of PB has been studied for the design of biosensors ${ }^{5,26}$ and $\mathrm{FCs}^{27,28}$, it has not yet been used in the construction of a biocathode for a single enzyme EBFC, whose anodic and cathodic reactions would be both based on the processes biocatalysed by GOx. This enzyme immobilized on the bioanode and biocathode would catalyze the oxidation of glucose to $\mathrm{H}_{2} \mathrm{O}_{2}$, which would be reduced on the surface of the biocathode. To design such biocathode, graphite rod (GR) electrode was coated with a composite of PB particles embedded in the PPCA shell (GR/PB-PPCA) and an additional layer of PPCA (GR/PB-PPCA/PPCA) by cyclic voltammetry (CV). Finally, GOx was covalently linked to the carboxyl groups of the PPCA (GR/PB-PPCA/PPCA-GOx). Immobilized GOx acted as a catalyst that oxidizes glucose by molecular $\mathrm{O}_{2}, \mathrm{~PB}$, meanwhile, acted as an electrocatalyst for the reduction of $\mathrm{H}_{2} \mathrm{O}_{2}$ formed during the enzymatic reaction. To achieve the best performance of the biocathode, preparation conditions were optimized by evaluating the generated signal to glucose. After optimization, the performance of the biocathode was investigated.

\section{Materials and methods}

Chemicals. GOx from Aspergillus niger (freeze-dried powder $360 \mathrm{U} / \mathrm{mg}$ protein), iron (III) chloride $\left(\mathrm{FeCl}_{3}\right)$ and $\mathrm{N}$-(3-dimethylaminopropyl)-N'-ethylcarbodiimide hydrochloride (EDC) were purchased from Carl Roth $\mathrm{GmbH}$. Potassium hexacyanoferrate (III) $\left(\mathrm{K}_{3}\left[\mathrm{Fe}(\mathrm{CN})_{6}\right]\right)$ were from Sigma-Aldrich. Pyrrole-2-carboxylic acid (PCA) and D-(+)-glucose monohydrate $\left(\mathrm{C}_{6} \mathrm{H}_{12} \mathrm{O}_{6} \times \mathrm{H}_{2} \mathrm{O}\right)$ were obtained from Alfa Aesar GmbH. Hydrogen peroxide $\left(\mathrm{H}_{2} \mathrm{O}_{2}\right)$ was obtained from Chempur and $\mathrm{N}$-hydroxysuccinimide (NHS) from Merck. All chemicals were of analytical grade. All aqueous solutions were prepared in ultra-high quality (UHQ) water, which was obtained using the DEMIWA rosa 5 water purification system (WATEK, Czech Republic). In addition, glucose solution was prepared at least $24 \mathrm{~h}$ before use to allow glucose to mutarotate and to reach equilibrium between $\alpha$ - and $\beta$-forms. $40.0 \mathrm{mg} / \mathrm{mL}$ solution of GOx was freshly prepared in sodium acetate-phosphate buffer solution composed of $0.05 \mathrm{mM} \mathrm{CH} \mathrm{COONa}_{3} 0.05 \mathrm{mM} \mathrm{Na}_{2} \mathrm{HPO}_{4}$ and $0.05 \mathrm{mM} \mathrm{NaH}_{2} \mathrm{PO}_{4}$ (A-PBS) and rapidly used. $0.5 \mathrm{M}$ solution of PCA was prepared in ethanol absolute.

Instrumentation. All electrochemical experiments as well as electrochemical synthesis of the PB-PPCA/ PPCA composite were performed using a computer-controlled potentiostat/galvanostat Autolab PGSTAT30 (Eco Chemie, Netherlands) driven by NOVA1.9 software. The voltammetric and amperometric cell was com- 
posed of Pt wire electrode as a counter electrode, $\mathrm{Ag} / \mathrm{AgCl}(3.0 \mathrm{M}$ of $\mathrm{KCl})$ reference electrode, and $\mathrm{GR}$ or modified GR electrode as a working electrode. The potentiometric cell was composed of $\mathrm{Ag} / \mathrm{AgCl}$ electrode and a modified GR electrode. All experiments were carried out inside a Faraday-cage at ambient temperature. Morphological studies of GR and modified GR electrodes were performed using scanning electron microscope (SEM) Helios Nanolab 650 (FEI, Netherlands).

GR electrode pre-treatment and preparation of the biochatode. GR electrodes were prepared by breaking a graphite rod $(15.0 \mathrm{~cm}$ in length, $3.0 \mathrm{~mm}$ in diameter and $99.999 \%$ purity, Sigma-Aldrich) into smaller rods of the required length. The broken rods were mechanically polished using very fine (P320) and finally ultrafine grit (P2000) sandpaper until the working surface of the electrode is completely smooth, and then were polished using a sheet of paper, washed with UHQ water, then ethanol and dried at room temperature. Finally, the side surface of the rod was isolated with a silicone tube so that only the working surface of the GR electrode was in contact with the solution in the electrochemical cell. The working surface area of GR electrodes thus prepared was $0.0707 \mathrm{~cm}^{2}$.

Pre-treated GR electrodes were used to perform electrochemical synthesis of the PB-PPCA/PPCA composite using CV. Under the optimized modification conditions, the pre-treated GR electrode, together with the reference and auxiliary electrodes, was immersed in an electrochemical cell filled with $5 \mathrm{~mL}$ of a solution consisting of $100.0 \mathrm{mM} \mathrm{HCl}, 100.0 \mathrm{mM} \mathrm{KCl}, 1.0 \mathrm{mM} \mathrm{FeCl}_{3}, 1.0 \mathrm{mM} \mathrm{K}_{3}\left[\mathrm{Fe}(\mathrm{CN})_{6}\right]$ and $35.0 \mathrm{mM}$ PCA. The potential was then scanned for 50 consecutive cycles in the range of potentials from -0.4 to $+1.0 \mathrm{~V}$ at a scan rate of $0.1 \mathrm{~V} / \mathrm{s}$. During this process, a composite of PB particles embedded in the PPCA shell (PB-PPCA) was formed on the GR electrode surface (GR/PB-PPCA). After synthesis of the PB-PPCA composite, the GR/PB-PPCA electrode was washed well with UHQ water and immersed in an electrochemical cell filled with $5 \mathrm{~mL}$ of A-PBS buffer solution with $0.1 \mathrm{M} \mathrm{KCl}$ additive (A-PBS-KCl), $\mathrm{pH}$ 6.0, and containing $200.0 \mathrm{mM}$ PCA. The potential was then scanned for 5 consecutive cycles in the range of potentials from -0.4 to $+1.0 \mathrm{~V}$ at a scan rate of $0.1 \mathrm{~V} / \mathrm{s}$. During this process, an additional layer of PPCA was formed on the GR/PB-PPCA electrode (GR/PB-PPCA/PPCA).

To modify the GR/PB-PPCA/PPCA electrode with GOx, the electrode was immersed in a tube filled with a mixture of $0.4 \mathrm{M}$ EDC and $0.1 \mathrm{M}$ NHS solutions in a ratio of 1:1 and left for $30 \mathrm{~min}$ at ambient temperature. The electrode was then removed from the mixture, washed with UHQ water, and immersed immediately in a $40 \mathrm{mg} / \mathrm{mL}$ GOx solution in A-PBS, $\mathrm{pH}$ 4.0, stirring the solution gently from time to time. The GOx was attached covalently by an amide bond to the electrode surface (GR/PB-PPCA/PPCA-GOx). Finally, the GR/PB-PPCA/ PPCA-GOx electrode was washed with UHQ water and to remove non-covalently bound enzyme was conditioned in A-PBS-KCl, $\mathrm{pH}$ 6.0, for $15 \mathrm{~min}$, stirring the solution gently from time to time. The prepared GR/ PB-PPCA/PPCA-GOx electrodes were stored in closed test tubes above a drop of A-PBS-KCl, $\mathrm{pH} 6.0$, at $+4{ }^{\circ} \mathrm{C}$ temperature until used in the experiments.

Electrochemical measurements. Electrochemical characterization of bare GR and modified GR electrodes was performed by CV, amperometric and potentiometric techniques. For half-cell measurements, threeelectrode cell was used for CV and amperometric measurements, while two-electrode cell was used for potentiometric measurements at open circuit or at an external load of $476 \mathrm{k} \Omega$. A-PBS-KCl buffer solution, $\mathrm{pH} 6.0$, was used as the electrolyte solution. The solution in the cell was continuously stirred with a magnetic stirrer at $450 \mathrm{rpm}$ during amperometric and potentiometric measurements. Meanwhile, CV measurements were performed without stirring; stirring was turned on only after the addition of glucose to mix the solution. Amperometric current dependence of the biocathode on glucose concentration was studied at $+100 \mathrm{mV}$ vs reference electrode. After stabilization of the background current or potential (base line), in the amperometric and potentiometric measurements respectively, a solution of glucose was injected in the electrochemical cell. The biocathode-generated signal was expressed as the change in cathodic current $(\Delta \mathrm{I})$ or the change in potential $(\triangle \mathrm{E})$ calculated from the signal recorded by the addition of glucose minus the baseline signal. During the $\mathrm{CV}$ measurements, the potential was scanned in the range of potentials from -0.2 to $+0.5 \mathrm{~V}$ at a scan rate of $0.1 \mathrm{~V} / \mathrm{s}$ or other as required, and the peak current was monitored. The results of all experiments were represented as a mean value of three independent measurements.

\section{Results and discussion}

In this research, a novel GR/PB-PPCA/PPCA-GOx biocomposite based biocathode was developed. CV was used for the electrochemical synthesis of the composite consisting of PB particles embedded in a PPCA shell (PB-PPCA) and for the formation of an additional PPCA layer over PB-PPCA (PB-PPCA/PPCA). To synthesize PB-PPCA on top of a GR electrode (GR/PB-PPCA), the electrode was immersed in an electrochemical cell filled with a solution consisting of $\mathrm{HCl}, \mathrm{KCl}, \mathrm{FeCl}_{3}, \mathrm{~K}_{3}\left[\mathrm{Fe}(\mathrm{CN})_{6}\right]$ and PCA, and polymerization was performed. The GR/PB-PPCA electrode was then immersed in an electrochemical cell filled with A-PBS-KCl buffer solution containing PCA and an additional PPCA layer (GR/PB-PPCA/PPCA) was synthesized. Finally, using activation of carboxyl groups of PPCA by a mixture of EDC and NHS, GOx molecules were linked to the PPCA via amide bonds (GR/PB-PPCA/PPCA-GOx). The design concept and operation of the biocathode are shown in Fig. 1. The operation of the biocathode can be explained by the electrocatalytic activity of PB towards to the reduction of $\mathrm{H}_{2} \mathrm{O}_{2}$ formed during GOx catalyzed oxidation of glucose. $\mathrm{Fe}(\mathrm{III})$ of PB after receiving the electron is electrochemically reduced to form PW, which has a high reduction activity ${ }^{25}$. The $\mathrm{H}_{2} \mathrm{O}_{2}$ formed during enzymatic reaction is reduced by $\mathrm{PW}$, and the $\mathrm{PW}$ is reoxidized to $\mathrm{PB}$. Due to the reversible redox activity of $\mathrm{PB}$, it acts as a renewable catalyst throughout the bioelectrochemical process. The amount of $\mathrm{H}_{2} \mathrm{O}_{2}$ formed during GOxcatalyzed reaction depends on the glucose concentration, thus the current or potential signal generated by the biocathode due to $\mathrm{H}_{2} \mathrm{O}_{2}$ reduction dependent on the glucose concentration. 


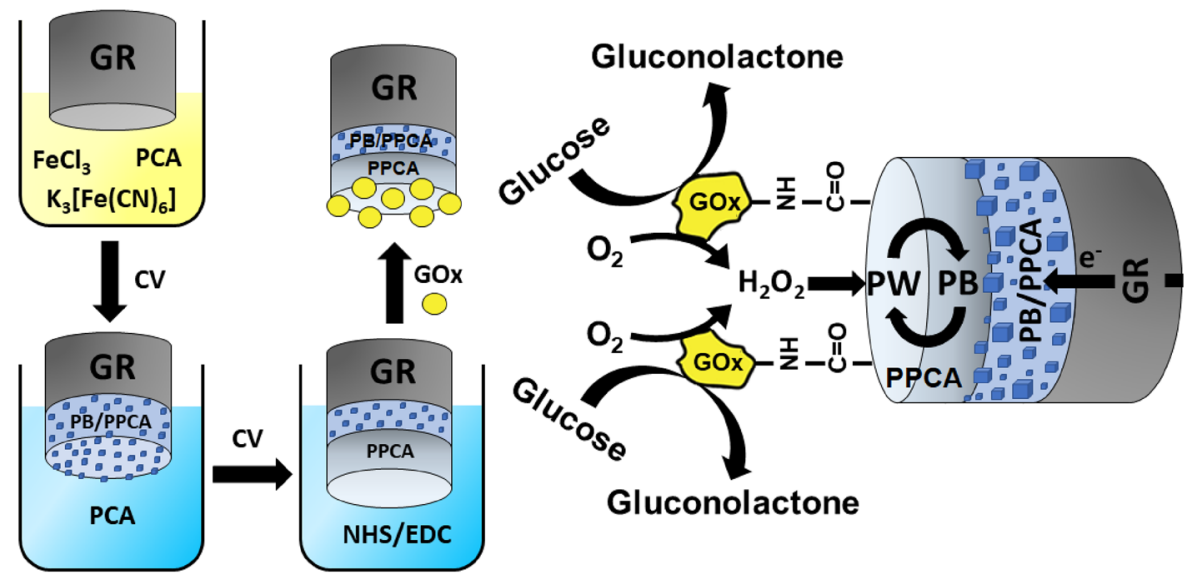

Figure 1. Scheme demonstrating fabrication and operation of the GR/PB-PPCA/PPCA-GOx biocathode.

Optimization of the biocathode preparation conditions. To obtain the best performance of the biocathode, its preparation conditions were optimized by estimating the magnitude of the generated current signal to glucose. Since the GR electrode was coated layer by layer with PB-PPCA/PPCA composite, the electrochemical synthesis conditions of PB-PPCA were first optimized. During optimization, PB-PPCA electrodes prepared under different conditions were modified with an additional layer of PPCA and immobilized GOx under constant conditions. The amperometric response of the GR/PB-PPCA/PPCA-GOx biocathodes to glucose in A-PBS-KCl buffer solution, expressed as cathodic current change $(\Delta \mathrm{I})$, was then investigated. Figure $2 \mathrm{~A}$ shows the experimental results obtained during the optimization of $\mathrm{FeCl}_{3}$ and $\mathrm{K}_{3}\left[\mathrm{Fe}(\mathrm{CN})_{6}\right]$ concentration. As can be seen, the current signal increased with increasing equimolar concentrations of $\mathrm{FeCl}_{3}$ and $\mathrm{K}_{3}\left[\mathrm{Fe}(\mathrm{CN})_{6}\right]$ up to an optimal concentration of $1.0 \mathrm{mM}$. Meanwhile, the optimal PCA concentration was found to be $35.0 \mathrm{mM}$ (Fig. 2B). It is likely that when the concentrations of $\mathrm{FeCl}_{3}$ and $\mathrm{K}_{3}\left[\mathrm{Fe}(\mathrm{CN})_{6}\right]$ are too high and the PCA is too low, $\mathrm{PB}$ particles from the resulting $\mathrm{PB}-\mathrm{PPCA}$ composite can diffuse into the solution, thus reducing the current generated by the biocathode. On the other hand, at too high concentration of PCA, a thick layer of PPCA is formed. Due to the low conductivity of this layer, the current generated is also reduced.

The current response to glucose was also depended on the potential scan rate (Fig. 2C) and the number of potential scans (Fig. 2D). The highest current response of the biocathode after addition of glucose was registered when a potential scan rate of $0.1 \mathrm{~V} / \mathrm{s}$ and 50 potential scans were used. During polymerization, a thick polymer shell is formed by applying more potential scans and higher scan rate. Meanwhile, with less potential scans and lower scan rate, the electrode surface may be inefficiently coated by PB-PPCA composite. This, as can be seen from the results, also affects the current generated by the biocathode.

During the optimization of the deposition of the additional PPCA layer, the dependence of the current signal on PCA concentration and potential scan rate was also observed. The highest current signal was registered when $200 \mathrm{mM}$ of PCA (Fig. 3A) and 5 potential scans (Fig. 3B) were used. Such results are related to the thickness of the resulting additional PPCA layer. The higher the PCA concentration and the number of potential scans, the thicker the additional PPCA layer. The thicker layer causes a decrease in the current generated by the biocathode. On the other hand, with a fuller and more uniform coating, more GOx molecules can be attached to the electrode surface. Based on the results of this study, $200 \mathrm{mM}$ PCA and 5 potential scans were selected as optimal conditions for the electrochemical polymerization of the additional PPCA layer on the GR/PB-PPCA electrode.

The concentration and $\mathrm{pH}$ of the GOx solution used for biocathode preparation were also optimized. In this work, a covalent amide coupling technique using a mixture of EDC and NHS was used for GOx immobilization. To find the most suitable $\mathrm{pH}$, after activation of the PPCA carboxyl groups, the GR/PB-PPCA/PPCA electrodes were immersed in GOx solution in A-PBS buffer with a certain $\mathrm{pH}$ from 4.0 to 7.0. The current response of the prepared biocathodes to glucose was then investigated. As can be seen from the results presented in Fig. 3C, the magnitude of the current signal was dependent on the $\mathrm{pH}$, and the highest current signal was registered at $\mathrm{pH}$ 4.0. These results were consistent with those obtained for GR electrodes modified with a nanobiocomposite composed of poly(1,10-phenanthroline-5,6-dione), PPCA, gold nanoparticles and GOx ${ }^{29}$, and can be explained by the pre-concentration of the enzyme near the electrode surface at this $\mathrm{pH}$, resulting in a higher amount of immobilized GOx. Very similar results were obtained when the influence of the concentration of GOx solution used during immobilization on the magnitude of the current signal generated by the biocathode was investigated. The increase in the enzyme concentration resulted in an increase in the current response of the biocathode to glucose and the highest response was recorded then the highest GOx concentration of $40 \mathrm{mg} / \mathrm{mL}$ was used (Fig. 3D). Because $40 \mathrm{mg} / \mathrm{mL}$ is a sufficiently high concentration, the effect of higher concentrations was not studied and this GOx concentration was chosen for use in biocathode preparation.

Electrochemical behaviour of the biocathode. Electrochemical behaviour was studied by recording cyclic voltammograms after an appropriate step of the biocathode preparation process. Figure 4A shows the corresponding cyclic voltammograms registered for GR, GR/PB, GR/PB-PPCA, GR/PB-PPCA/PPCA, and GR/ 


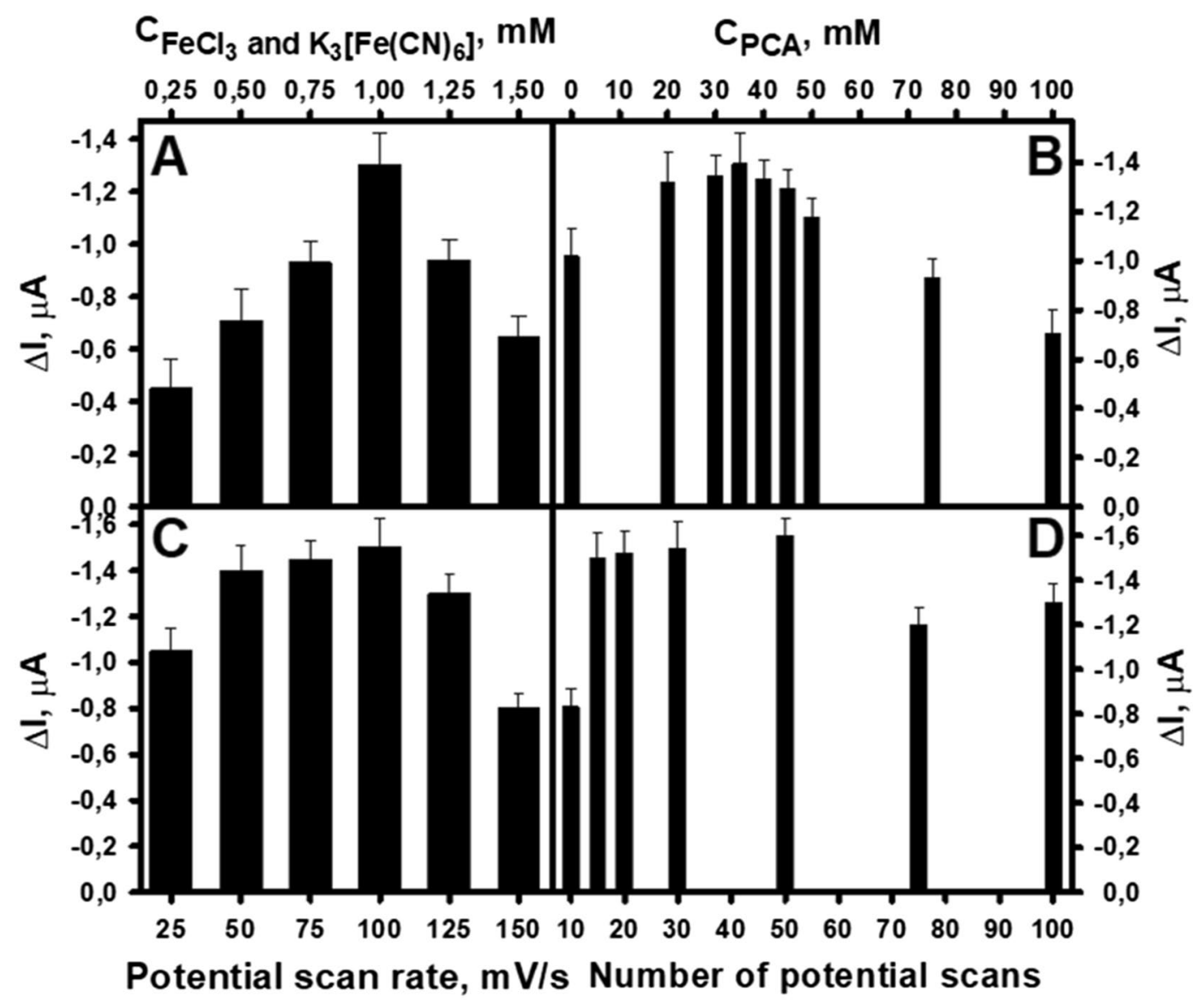

Figure 2. Optimization of electrochemical PB-PPCA synthesis conditions: concentration of $\mathrm{FeCl}_{3}, \mathrm{~K}_{3}\left[\mathrm{Fe}(\mathrm{CN})_{6}\right]$ (A) and PCA (B), potential scan rate (C) and number of scans (D). Constant experimental conditions: $45.0 \mathrm{mM}$ of PCA, 15 scans at potential scan rate of $0.05 \mathrm{~V} / \mathrm{s}(\mathrm{A}) ; 1.0 \mathrm{mM}$ of $\mathrm{FeCl}_{3}$ and $\mathrm{K}_{3}\left[\mathrm{Fe}(\mathrm{CN})_{6}\right], 15$ scans at potential scan rate of $0.05 \mathrm{~V} / \mathrm{s}(\mathrm{B}) ; 1.0 \mathrm{mM}$ of $\mathrm{FeCl}_{3}$ and $\mathrm{K}_{3}\left[\mathrm{Fe}(\mathrm{CN})_{6}\right], 35.0 \mathrm{mM}$ of PCA, 15 scans $(\mathrm{C}) ; 1.0 \mathrm{mM}$ of $\mathrm{FeCl}_{3}$ and $\mathrm{K}_{3}\left[\mathrm{Fe}(\mathrm{CN})_{6}\right], 35.0 \mathrm{mM}$ of PCA, potential scan rate of $0.10 \mathrm{~V} / \mathrm{s}(\mathrm{D})$. Experimental conditions for the synthesis of an additional PPCA layer: $100.0 \mathrm{mM}$ of PCA, potential scan rate of $0.1 \mathrm{~V} / \mathrm{s}, 10$ scans. GOx concentration: $40.0 \mathrm{mg} / \mathrm{mL}$ at $\mathrm{pH} 4.0$. Measurement conditions: applied potential of $+0.1 \mathrm{mV}, \mathrm{A}-\mathrm{PBS}-\mathrm{KCl}, \mathrm{pH}$ 6.0, $7.97 \mathrm{mM}$ of glucose.

PB-PPCA/PPCA-GOx electrodes. As can be seen, in the voltammogram recorded for the GR electrode, there are no oxidation and reduction current peaks (redox peaks) in a potential range between -0.2 and $+0.5 \mathrm{~V} \mathrm{vs} \mathrm{Ag/}$ $\mathrm{AgCl}$. Meanwhile, for the other electrodes studied, a pair of well-defined redox peaks due to the electrochemical reaction of high-spin ferric ions in $\mathrm{PB}\left(\mathrm{Fe}^{2+} / \mathrm{Fe}^{3+} \text { transition }\right)^{24}$ were recorded in this potential range. The positions of the characteristic redox peaks and the distances between them are given in Table 1 .

The occurrence of characteristic redox peaks and the increase in peak current compared to the GR electrode indicate successive deposition of PB on all modified electrodes. The observed redox peaks potential values were similar to those described in the literature for PB modified electrodes ${ }^{30-32}$. In addition, as can be seen from Fig. 4A, the cyclic voltammograms of the GR/PB-PPCA, GR/PB-PPCA/PPCA and GR/PB-PPCA/PPCA-GOx electrodes showed a significant increase in redox peaks intensity compared to the GR/PB electrode. These results demonstrated that the presence of PCA in the electropolymerization solution increases the amount of PB on the electrode surface due to its distribution inside the polymer matrix. Meanwhile, the decrease in the intensity of the GR/PB-PPCA/PPCA redox peaks compared to GR/PB-PPCA could be explained by the formation of an additional PPCA layer. Because electropolymerization was carried out in an aqueous medium without removal of oxygen, the PPCA layer formed is low conductive or even non-conductive ${ }^{29}$. Therefore, the formation of an additional layer of PPCA causes a decrease in the intensity of the redox peaks. For the GR/PB-PPCA/PPCA-GOx, an even greater decrease in redox peaks intensity was observed due to nonconducting nature of enzyme ${ }^{33,34}$ immobilized on the surface. In addition, as shown in Fig. $4 \mathrm{~A}$, the presence of $10.0 \mathrm{mM}$ glucose in A-PBS-KCl buffer solution caused an increase in GR/PB-PPCA/PPCA-GOx reduction peak current by approximately $29 \mu \mathrm{A}$ (black line). This indicates that the $\mathrm{H}_{2} \mathrm{O}_{2}$ formed during the enzymatic glucose oxidation reaction was electrochemically reduced on the surface of the biocathode.

The cyclic voltammograms of the GR/PB-PPCA/PPCA-GOx biocathode in A-PBS-KCl, pH 6.0, at different potential scan rates are shown in Fig. 4B. As can be seen, the intensity of the redox peaks varied with the potential scan rate and was directly proportional to the scan rate (Fig. $4 \mathrm{C})$. The linear relationship between oxidation $\left(\mathrm{I}_{\mathrm{ox}}\right)$ 


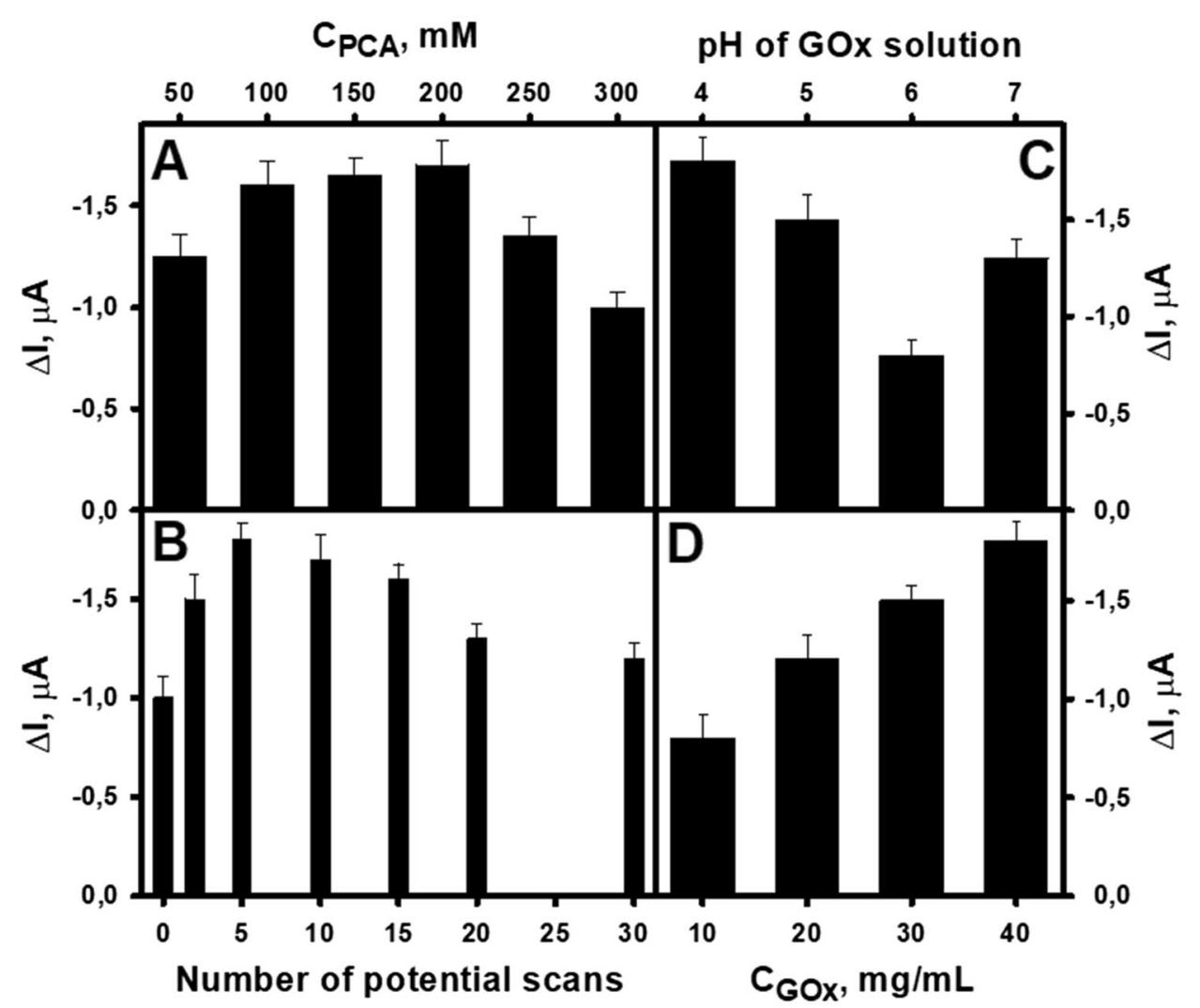

Figure 3. Optimization of additional PPCA layer electrochemical synthesis and GOx immobilization conditions. (A) Optimization of PCA concentration. Constant experimental conditions: potential scan rate of $0.1 \mathrm{~V} / \mathrm{s}, 10$ scans. (B) Optimization of the number of scans. Constant experimental conditions: $200.0 \mathrm{mM}$ of PCA, potential scan rate of $0.1 \mathrm{~V} / \mathrm{s}$. Optimization of GOx solution $\mathrm{pH}(\mathbf{C})$ and concentration (D). Experimental conditions for the synthesis of PB-PPCA: $1.0 \mathrm{mM}$ of $\mathrm{FeCl}_{3}$ and $\mathrm{K}_{3}\left[\mathrm{Fe}(\mathrm{CN})_{6}\right], 35.0 \mathrm{mM}$ of PCA, potential scan rate of $0.1 \mathrm{~V} / \mathrm{s}, 50$ scans. GOx concentration: $40.0 \mathrm{mg} / \mathrm{mL}$ at $\mathrm{pH} 4.0(\mathrm{~A}-\mathrm{C})$. GOx solution $\mathrm{pH}: 4.0(\mathrm{~A}, \mathrm{~B}, \mathrm{D})$. Measurement conditions: applied potential of + 0.1 V, A-PBS-KCl, $\mathrm{pH} 6.0,7.97 \mathrm{mM}$ of glucose.

and reduction $\left(\mathrm{I}_{\text {red }}\right)$ current peaks and potential scan rate and the ratio of $\mathrm{I}_{\text {ox }} / \mathrm{I}_{\text {red }}$ almost equal to unity, revealed the quasi-reversible and surface-confined ${ }^{32}$ electrochemical behaviour of the PB in PB-PPCA/PPCA-GOx biocomposite, in which $\mathrm{PB}$ is reduced to $\mathrm{PW}$ and is re-oxidized to $\mathrm{PB}$.

Morphological study. The surface morphology of bare GR and GR at different stages of the modifying process (GR/PB, GR/PB-PPCA, GR/PB-PPCA/PPCA, and GR/PB-PPCA/PPCA-GOx) was studied using SEM at $3 \mathrm{kV}$ accelerating voltage, 50,000 magnification and $0.8 \mathrm{nA}$ current. The SEM images in Fig. 5 clearly demonstrate changes in surface morphology during GR modification.

As can be seen, the GR surface is quite smooth with minor defects occurring during surface polishing. (Fig. 5A). Meanwhile, a completely different surface morphology was observed for the other electrodes. Cubic PB structures of approximately $100 \mathrm{~nm}$ in size are observed on the surface of GR/PB (Fig. 5B), similar to those published by other authors ${ }^{32,35}$. However, as can be seen, the surface coating is very uneven with large, uncoated $\mathrm{GE}$ areas. Not uniform coating may be related to the removal of $\mathrm{PB}$ particles from the surface during synthesis and electrode washing after synthesis. Meanwhile, the presence of PPCA in the synthesis solution resulted in a much better and more uniform coating with a higher amount of $\mathrm{PB}$ on the electrode surface (Fig. 5C). However, the characteristic cubic structure of $\mathrm{PB}$ was no longer visible. This change in morphology may be related to the disruption of the growth of $\mathrm{PB}$ particles into the cubic framework due to the spatial limitations resulting from the embedment of $\mathrm{PB}$ particles into the growing PPCA shell ${ }^{36}$. PB-PPCA coating showed an irregular globular morphology, which was in agreement with other reports for $\mathrm{PB}$ and polymer composites ${ }^{36,37}$. A rougher coating with larger structures compared to GR/PB-PPCA as well as globular surface morphology was observed for GR/ PB-PPCA/PPCA (Fig. 5D). This indicates that PB-PPCA was coated with an additional layer of PPCA. Similar surface morphology, with slightly larger structures was observed for GR/PB-PPCA/PPCA-GOx (Fig. 5E). The results of surface morphology studies confirmed the assumption that PB was incorporated into PPCA during the formation of the PB-PPCA layer, and an additional PPCA layer was formed on the surface of the PB-PPCA. 


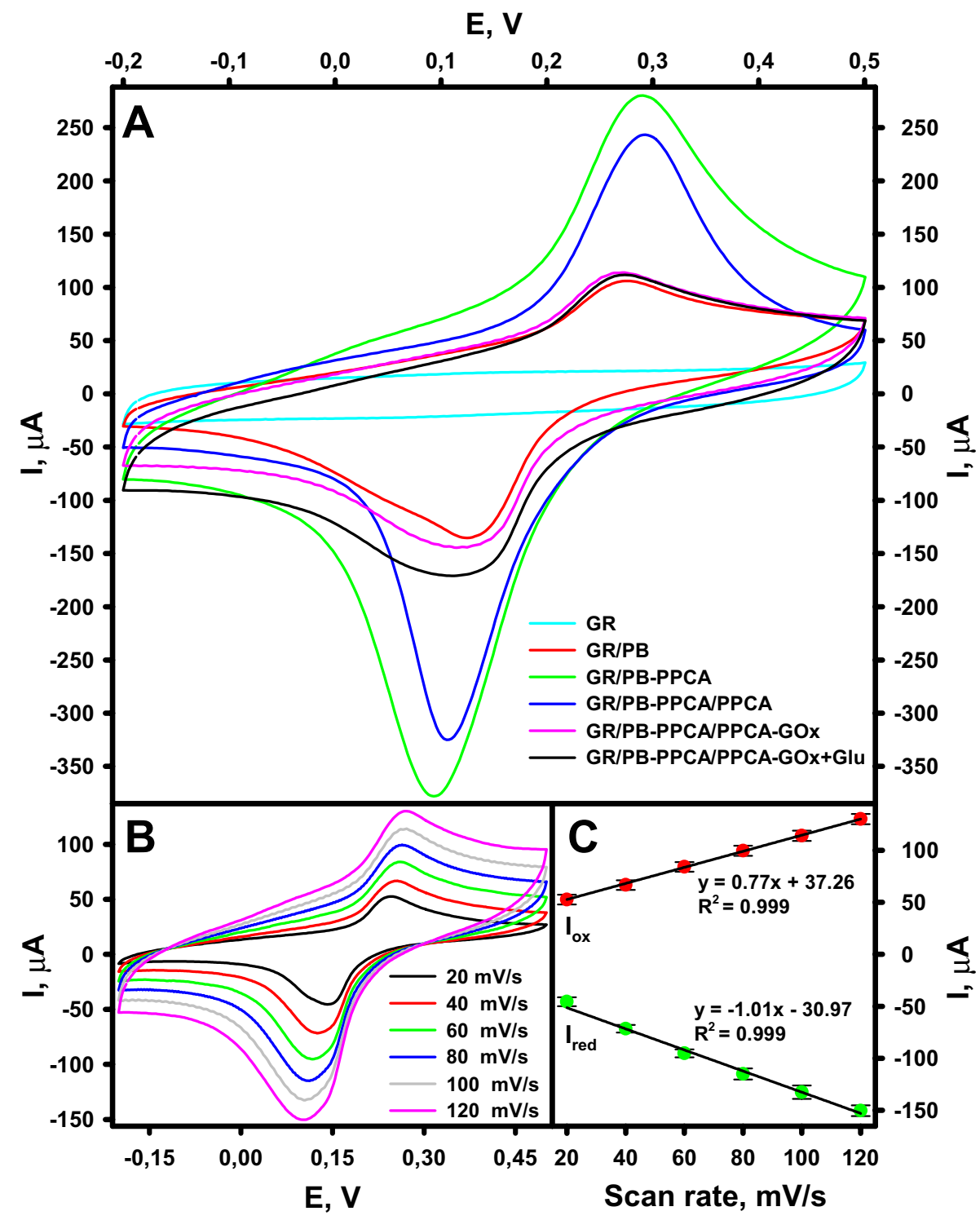

Figure 4. (A) Cyclic voltammograms for electrodes obtained after an appropriate step of the biocathode preparation process recorded in pure A-PBS- $\mathrm{KCl}, \mathrm{pH} 6.0$, or in $10 \mathrm{mM}$ glucose (Glu) solution in A-PBS-KCl, $\mathrm{pH} 6.0$, at a scan rate of $100 \mathrm{mV} / \mathrm{s}$. (B) Cyclic voltammograms for biocathode recorded in A-PBS-KCl, $\mathrm{pH}$ 6.0, at various scan rates. (C) Plots of peak current vs scan rate.

\begin{tabular}{|l|l|c|l|l|l|}
\hline Electrode & $\mathbf{E}_{\text {ox }}, \mathbf{m V}$ & $\mathbf{E}_{\text {red }}, \mathbf{m V}$ & $\Delta \mathrm{E}, \mathbf{m V}$ & $\mathbf{I}_{\text {ox }}, \boldsymbol{\mu A}$ & $\mathbf{I}_{\text {red }} \boldsymbol{\mu A}$ \\
\hline GR/PB & $277.8 \pm 4.1$ & $120.7 \pm 4.4$ & $155.6 \pm 3.8$ & $109.1 \pm 7.1$ & $-128.4 \pm 9.5$ \\
\hline GR/PB-PPCA & $290.6 \pm 4.9$ & $93.3 \pm 5.9$ & $197.2 \pm 1.1$ & $268.5 \pm 12.7$ & $-362.1 \pm 14.2$ \\
\hline GR/PB-PPCA/PPCA & $291.3 \pm 5.3$ & $104.0 \pm 4.1$ & $187.3 \pm 1.3$ & $232.8 \pm 10.9$ & $-311.7 \pm 17.1$ \\
\hline GR/PB-PPCA/PPCA-GOx & $272.4 \pm 6.1$ & $103.5 \pm 4.6$ & $168.9 \pm 3.9$ & $114.1 \pm 12.4$ & $-135.6 \pm 15.0$ \\
\hline
\end{tabular}

Table 1. Voltammetric parameters of different modified GR electrodes obtained in A-PBS-KCl, $\mathrm{pH} 6.0$, at a scan rate of $0.1 \mathrm{~V} / \mathrm{s}$.

Study of the biocathode response to glucose. Figure 6 shows the influence of glucose concentrations on the reduction current, the potential at an external load of $476 \mathrm{k} \Omega$ (curve a) and the open-circuit potential (OCP) (curve b) generated by the GR/PB-PPCA/PPCA-GOx biocathode.

Three-electrode cell consisting of $\mathrm{Pt}$ wire counter electrode, $\mathrm{Ag} / \mathrm{AgCl}$ reference electrode, and GR/PB-PPCA/ PPCA-GOx biocathode was used for current measurements, while two-electrode cell consisting of $\mathrm{Ag} / \mathrm{AgCl}$ 


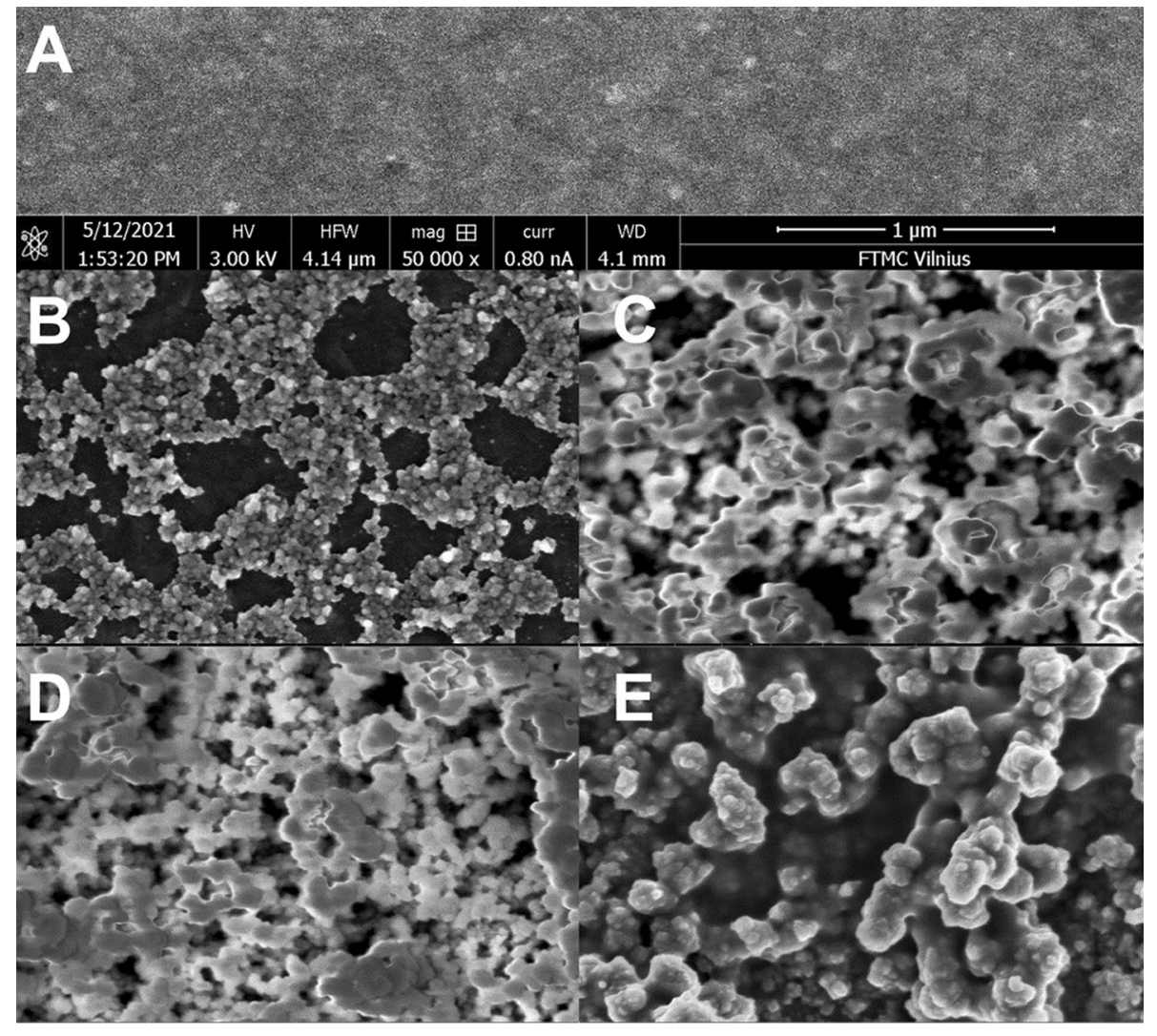

Figure 5. SEM images of GR (A) and GR/PB (B), GR/PB-PPCA (C), GR/PB-PPCA/PPCA (D) and GR/ PB-PPCA/PPCA-GOx (E) modified electrodes.

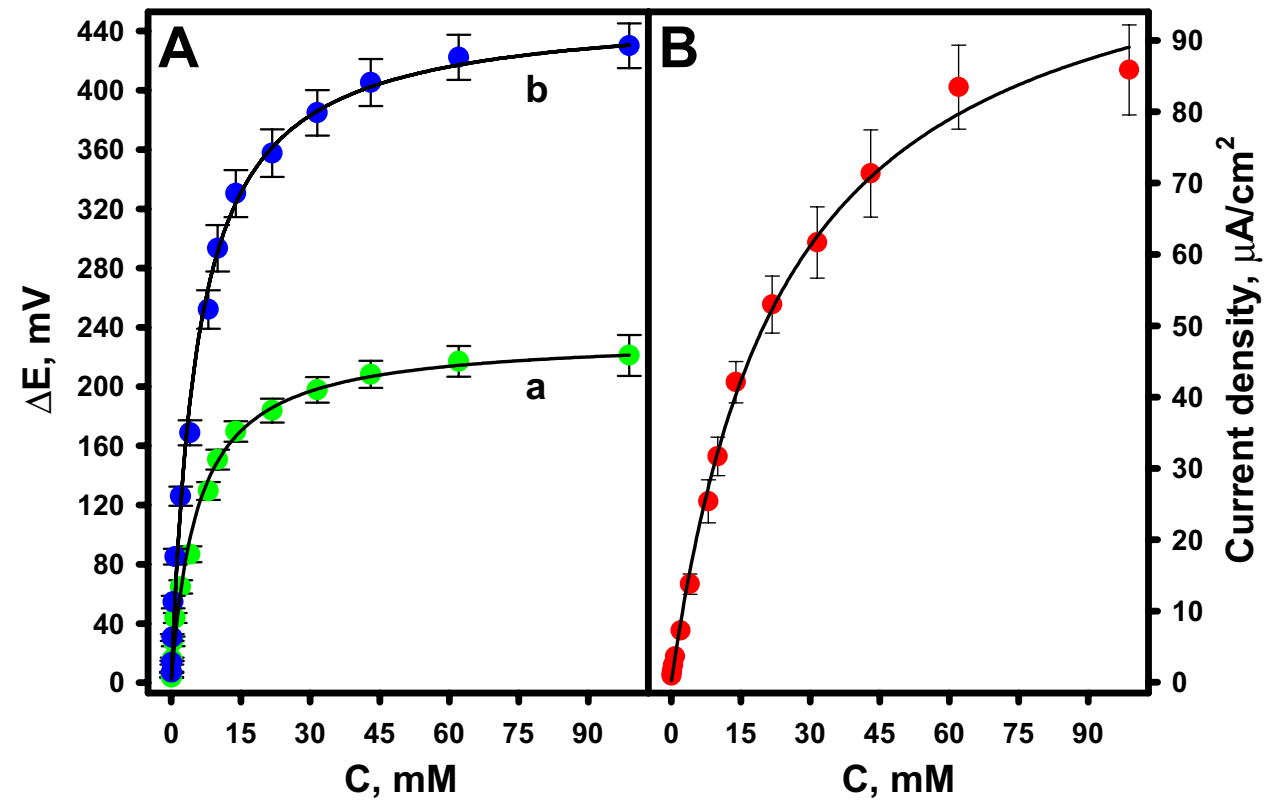

Figure 6. Dependence of potential (A) and current density (B) at open-circuit (curve b) and at an external load of $476 \mathrm{k} \Omega$ (curve a) generated by the biocathode on glucose concentration. Measurements conditions: A-PBS$\mathrm{KCl}, \mathrm{pH} 6.0$, applied potential of $+0.1 \mathrm{~V}$ for amperometric measurements. 


\begin{tabular}{|l|l|l|l|}
\hline Biocathode & OCP, $\mathbf{m V}$ & Current density, $\boldsymbol{\mu} \mathbf{A} / \mathbf{c m}^{2}$ & References \\
\hline MWBP/BOx & $520 \mathrm{vs} \mathrm{Ag} / \mathrm{AgCl}$ & - & 38 \\
\hline CNBP/Lac & $557 \mathrm{vs} \mathrm{SCE}$ & 50.0 & 39 \\
\hline PGE/PANI/MWCNT/Lac & $528 \mathrm{vs} \mathrm{Ag/AgCl}$ & 1209.2 & 40 \\
\hline MWCNT/Lac & $430 \mathrm{vs} \mathrm{SCE}$ & - & 41 \\
\hline DWCNT/HRP/GOx & $380 \mathrm{vs} \mathrm{SCE}$ & 115 & 23 \\
\hline GR/MWCNT/HRP/GOx & $550 \mathrm{vs} \mathrm{Ag/AgCl}$ & - & 42 \\
\hline SPE/PB/ChOx & - & 8.8 & 5 \\
\hline CNBP/PTH/BOx & $520 \mathrm{vs} \mathrm{Ag/AgCl}$ & - & 43 \\
\hline AlO/CoNT/PANI/Lac & $590 \mathrm{vs} \mathrm{Ag/AgCl}$ & 140.12 & 44 \\
\hline P2/BOx/PEGDGE & $420 \mathrm{vs} \mathrm{Ag} / \mathrm{AgCl}$ & - & 45 \\
\hline GR/PB-PPCA/PPCA-GOx & $430 \mathrm{vs} \mathrm{Ag/AgCl}$ & 85.86 & This work \\
\hline
\end{tabular}

Table 2. Comparison of the performance of some biocathodes described in the literature with the biocathode developed in this work. MWBP - multi-walled carbon nanotube paper; BOx - bilirubin oxidase; CNBP - carbon nanotube buckypaper; PGE - pencil graphite electrode; MWCNT - multi-walled carbon nano tubes; MWCNT - double-walled carbon nano tubes; HRP - horseradish peroxidase; SPE - screen-printed electrode; ChOx - cholesterol oxidase; PTH - polythiophene; AlO - anodic aluminium oxide template; CoNT - copper nanotubes; PEGDGE - poly(ethylene glycol) diglycidyl ether; P2 - poly(1-vinylimidazole-co-[2(methacryloyloxy)ethyl]trimethylammoniumchloride)-[Os(bpy) $\left.{ }_{2} \mathrm{Cl}\right]^{+}$

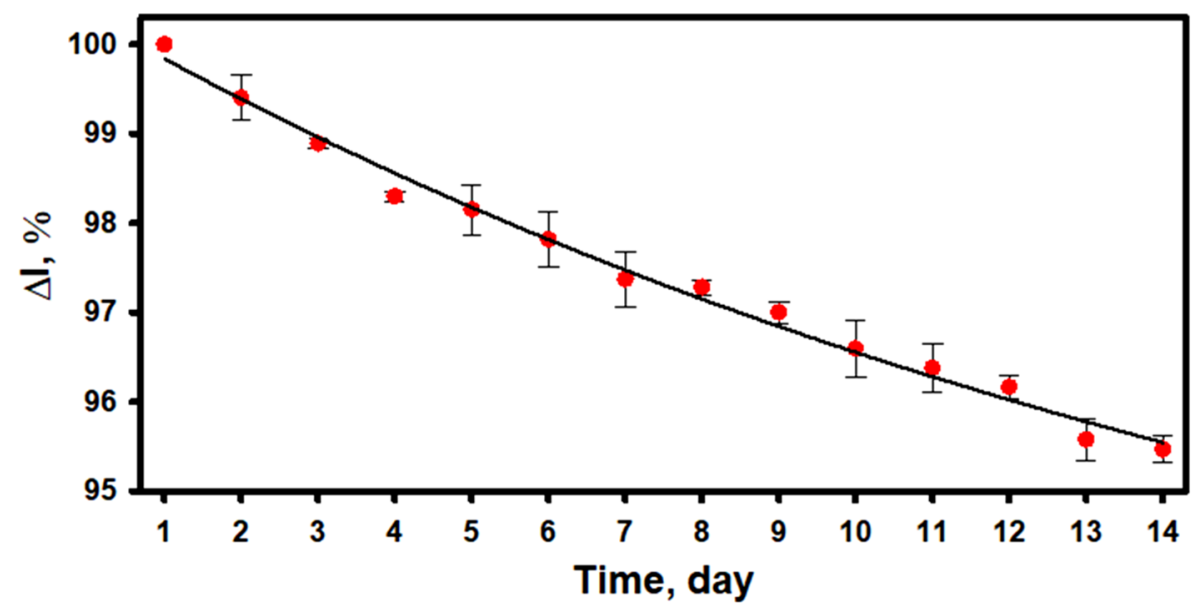

Figure 7. Changes of the biocathode current signal vs time. Measurements conditions: A-PBS-KCl, $\mathrm{pH} 6.0$, $10.0 \mathrm{mM}$ of glucose, applied potential of $+0.1 \mathrm{~V}$.

reference electrode and GR/PB-PPCA/PPCA-GOx biocathode was used for potentiometric measurements at open circuit or at an external load of $476 \mathrm{k} \Omega$. The measurements were performed in $\mathrm{O}_{2}$-saturated A-PBS-KCl solution, $\mathrm{pH} 6.0$, at different glucose concentrations from 0.05 to $98.86 \mathrm{mM}$. The error bars correspond to the values of each concentration recorded by the three different biocathodes and illustrate the reproducibility of the measurements and the fabrication of the biocathode.

As can be seen, a linear increase in biocathode response was observed with increasing glucose concentration up to about $10.00 \mathrm{mM}$. With further increase in glucose concentration, a non-linear increase in the biocathode response was observed up to $98.86 \mathrm{mM}$, and then the recorded signal became saturated because the catalytic reaction was inhibited at higher glucose concentrations. As a result, the amount of $\mathrm{H}_{2} \mathrm{O}_{2}$ formed during the enzymatic reaction became constant. The maximal current density of $85.86 \pm 6.30 \mu \mathrm{A} / \mathrm{cm}^{2}$, the potential of $221.03 \pm 13.90 \mathrm{mV}$, and the OCP of $430.15 \pm 15.10 \mathrm{mV}$ at $98.86 \mathrm{mM}$ glucose were recorded. Meanwhile, at $10.00 \mathrm{mM}$ glucose, the recorded current density was $31.68 \pm 2.70 \mu \mathrm{A} / \mathrm{cm}^{2}$, the potential was $150.73 \pm 6.70 \mathrm{mV}$ and the OCP was $293.34 \pm 15.70 \mathrm{mV}$. The performance of the developed biocathode was comparable to the previously reported biocathodes. Some of them are listed in Table $2 .$.

Stability study of the biocathode. To investigate the stability of the developed biocathode, the current signal generated by it was monitored over a period of 14 days. The measurements were carried out in A-PBS$\mathrm{KCl}$ buffer solution, $\mathrm{pH} 6.0$, containing $10.0 \mathrm{mM}$ of glucose. Between measurements, the biocathode was stored at $+4{ }^{\circ} \mathrm{C}$ in a closed vessel above a drop of A-PBS-KCl buffer solution, $\mathrm{pH}$ 6.0. As can be seen from the experimental data presented in Fig. 7, current generated by the GR/PB-PPCA/PPCA-GOx biocathode after addition 
of glucose gradually decreased over a period of 14 days. However, the biocathode maintained $95.53 \pm 0.15 \%$ of the initial response after 14 days. Such a relatively small decrease in current response may be associated with the covalent immobilization of $\mathrm{GOx}^{46}$ and the stability of PB-PPCA/PPCA composite.

\section{Conclusion}

In this study, a graphite rod electrode modified with a biocomposite composed of Prussian blue, poly(pyrrole2-carboxylic acid) and glucose oxidase (GOx) was proposed as a potential biocathode for glucose-powered single enzyme biofuel cell. PPCA allowed covalent immobilization of GOx, PB, meanwhile, exhibited electrocatalytic activity to the reduction of $\mathrm{H}_{2} \mathrm{O}_{2}$ formed during GOx-catalysed oxidation of glucose. The developed biocathode proved to be able to generate a current density of $31.68 \pm 2.70 \mu \mathrm{A} / \mathrm{cm}^{2}$ and open-circuit potential of $276.74 \pm 15.70 \mathrm{mV}$ in $\mathrm{O}_{2}$-saturated $10 \mathrm{mM}$ glucose-buffered solution at $\mathrm{pH}$ 6.0. A maximum open-circuit potential of $405.80 \pm 15.10 \mathrm{mV}$ was recorded at $98.86 \mathrm{mM}$ glucose. In addition, the biocathode showed good operational stability, maintaining $95.53 \pm 0.15 \%$ of the initial current response after 14 days. This study demonstrates the potential of the designed biocathode to develop glucose-powered single enzyme biofuel cell, therefore, further work will focus on its development. The advantage of such biofuel cells is that they do not require two enzymes, which simplifies the system, reduces costs and lead to avoid disparities in the operating conditions of the enzymes used. It is likely that the use of the designed biocathode will improve the performance of the biofuel cell to be developed. In addition, this simple biocathode design can serve to develop single enzyme biofuel cells based on other oxidases.

Received: 7 June 2021; Accepted: 23 August 2021

Published online: 17 September 2021

\section{References}

1. Wang, L. et al. Enzymatic biofuel cell: Opportunities and intrinsic challenges in futuristic applications. Adv. Energy Sustain. Res. https://doi.org/10.1002/aesr.202100031 (2021).

2. Xiao, X. et al. Tackling the challenges of enzymatic (bio)fuel cells. Chem. Rev. 119, 9509-9558 (2019).

3. Goff, A. L., Holzinger, M. \& Cosnier, S. Recent progress in oxygen-reducing laccase biocathodes for enzymatic biofuel cells. Cell. Mol. Life Sci. 72, 941-952 (2015).

4. Heller, A. Miniature biofuel cells. Phys. Chem. Chem. Phys. 6, 209-216 (2004).

5. Sekretaryova, A. N. et al. Cholesterol self-powered biosensor. Anal. Chem. 86, 954c0-9547 (2014).

6. Shitanda, I. et al. High-power lactate/ $\mathrm{O}_{2}$ enzymatic biofuel cell based on carbon cloth electrodes modified with MgO-templated carbon. J. Power Sources 436, 226844. https://doi.org/10.1016/j.jpowsour.2019.226844 (2019).

7. Galindo-de-la-Rosa, J., Ortiz-Ortega, E., Lopez-Gonzalez, B., Arriaga, L. G. \& Ledesma-Garcia, J. Microfluidic biofuel cell based on cholesterol oxidase/laccase enzymes. J. Phys. Conf. Ser. 1407, 012096. https://doi.org/10.1088/1742-6596/1407/1/012096 (2019).

8. Ramanavicius, A., Kausaite, A. \& Ramanaviciene, A. Enzymatic biofuel cell based on anode and cathode powered by ethanol. Biosens. Bioelectron. 24, 767-772 (2008).

9. Zhong, Z. et al. A high-performance glucose/oxygen biofuel cell based on multi-walled carbon nanotube films with electrophoretic deposition. J. Electroanal. Chem. 823, 723-729 (2018).

10. Hou, C., Yang, D., Liang, B. \& Liu, A. Enhanced performance of a glucose $/ \mathrm{O}_{2}$ biofuel cell assembled with laccase-covalently immobilized three-dimensional macroporous gold film-based biocathode and bacterial surface displayed glucose dehydrogenase-based bioanode. Anal. Chem. 86, 6057-6063 (2014).

11. Ramanavicius, A., Kausaite, A. \& Ramanaviciene, A. Biofuel cell based on direct bioelectrocatalysis. Biosens. Bioelectron. 20, 1962-1967 (2005).

12. Krikstolaityte, V. et al. Biofuel cell based on anode and cathode modified by glucose oxidase. Electroanalysis 25, 2677-2683 (2013).

13. Xu, S. \& Minteer, S. D. Enzymatic biofuel cell for oxidation of glucose to $\mathrm{CO}_{2}$. ACS Catal. 2, 91-94 (2012).

14. Abreu, C. et al. Glucose oxidase bioanodes for glucose conversion and $\mathrm{H}_{2} \mathrm{O}_{2}$ production for horseradish peroxidase biocathodes in a flow through glucose biofuel cell design. J. Power Sources 392, 176-180 (2018).

15. Kim, R. E., Hong, S.-G., Ha, S. \& Kim, J. Enzyme adsorption, precipitation and crosslinking of glucose oxidaseand laccase on polyaniline nanofibers for highly stable enzymaticbiofuel cells. Enzyme Microb. Technol. 66, 35-41 (2014).

16. Zhou, M. \& Wang, J. Biofuel cells for self-powered electrochemical biosensing and logic biosensing: A review. Electroanalysis 24, 197-209 (2012).

17. Chen, Y., Ji, W., Yan, K., Gao, J. \& Zhang, J. Fuel cell-based self-powered electrochemical sensors for biochemical detection. Nano Energy 61, 173-193 (2019).

18. Gonzalez-Solino, C. \& Lorenzo, M. D. Enzymatic fuel cells: Towards self-powered implantable andwearable diagnostics. Biosensors (Basel) 8, 11. https://doi.org/10.3390/bios8010011 (2018).

19. Haque, S. U., Nasar, A., Inamuddin, \& Rahman, M. M. Applications of chitosan (CHI)-reduced graphene oxide (rGO)-polyaniline (PAni) conducting composite electrode for energy generation in glucose biofuel cell. Sci. Rep. 10, 10428. https://doi.org/10.1038/ s41598-020-67253-6 (2020).

20. Kang, Z. et al. A novel three-dimensional carbonized PANI1600@CNTs network for enhanced enzymatic biofuel cell. Biosens. Bioelectron. 101, 60-65 (2018).

21. Kang, Z., Zhang, Y.-H.P.J. \& Zhu, Z. A shriveled rectangular carbon tube with the concave surface for highperformance enzymatic glucose/ $\mathrm{O}_{2}$ biofuel cells. Biosens. Bioelectron. 132, 76-83 (2019).

22. Ramanavicius, A. et al. Biofuel cell based on glucose oxidase from Penicillium Funiculosum 46.1 and horseradish peroxidase. Chem. Eng. J. 264, 165-173 (2015).

23. Agnes, C., Reuillard, B., Goff, A. L., Holzinger, M. \& Cosnier, S. A double-walled carbon nanotube-based glucose/ $\mathrm{H}_{2} \mathrm{O}_{2}$ biofuel cell operating under physiological conditions. Electrochem. Commun. 34, 105-108 (2013).

24. Cinti, S., Arduini, F., Moscone, D., Palleschi, G. \& Killard, A. J. Development of a hydrogen peroxide sensor based on screen-printed electrodes modified with inkjet-printed Prussian blue nanoparticles. Sensors (Basel) 14, 14222-14234. https://doi.org/10.3390/ s140814222 (2014)

25. Li, L., Peng, J., Chu, Z., Jiang, D. \& Jin, W. Single layer of graphene/Prussian blue nano-grid as the low-potential biosensors with high electrocatalysis. Electrochim. Acta 217, 210-217 (2016).

26. Luo, J., Li, T. \& Yang, M. Detection protein biomarker with gold nanoparticles functionalized hollow mesoporous Prussian blue nanoparticles as electrochemical probes. Chin. Chem. Lett. 31, 202-204 (2020).

27. Silveira, G., de Aquino Neto, S. \& Schneedorf, J. M. Development, characterization and application of a low-cost single chamber microbial fuel cell based on hydraulic couplers. Energy 208, 118395. https://doi.org/10.1016/j.energy.2020.118395 (2020). 
28. Shaegh, S. A. M., Nguyen, N.-T., Ehteshami, S. M. M. \& Chan, S. H. A membraneless hydrogen peroxide fuel cell using Prussian blue as cathode material. Energy Environ. Sci. 5, 8225-8228 (2012).

29. Kausaite-Minkstimiene, A., Glumbokaite, L., Ramanaviciene, A. \& Ramanavicius, A. Reagent-less amperometric glucose biosensor based on nanobiocomposite consisting of poly(1,10-phenanthroline-5,6-dione), poly(pyrrole-2-carboxylic acid), gold nanoparticles and glucose oxidase. Microchem. J. 154, 104665. https://doi.org/10.1016/j.microc.2020.104665 (2020).

30. Ojani, R., Hamidi, P. \& Raoof, J.-B. Efficient nonenzymatic hydrogen peroxide sensor in acidic media based on Prussian blue nanoparticles-modified poly(o-phenylenediamine)/glassy carbon electrode. Chin. Chem. Lett. 27, 481-486 (2016).

31. Qiu, W. et al. Graphene oxide directed in-situ synthesis of Prussian blue for non-enzymatic sensing of hydrogen peroxide released from macrophages. Mater. Sci. Eng. C Mater. Biol. Appl. 72, 692-700 (2017).

32. Lee, P. K., Nia, P. M. \& Woi, P. M. Facile self-assembled Prussian blue-polypyrrole nanocomposites on glassy carbon: Comparative synthesis methods and its electrocatalytic reduction towards $\mathrm{H}_{2} \mathrm{O}_{2}$. Electrochim. Acta 246, 841-852 (2017).

33. Tang, W., Li, L., Wu, L., Gong, J. \& Zeng, X. Glucose biosensor based on a glassy carbon electrode modified with polythionine and multiwalled carbon nanotubes. PLoS ONE 9, e95030. https://doi.org/10.1371/journal.pone.0095030 (2014).

34. Kim, B. C. et al. Fabrication of enzyme-based coatings on intact multi-walled carbon nanotubes as highly effective electrodes in biofuel cells. Sci. Rep. 7, 40202. https://doi.org/10.1038/srep40202 (2017).

35. Baggio, B. F. et al. Morphology and structure of electrodeposited Prussian blue and Prussian white thin films. Materials 12, 1103. https://doi.org/10.3390/ma12071103 (2019).

36. Hostert, L., de Alvarenga, G., Marchesi, L. F., Soares, A. L. \& Vidotti, M. One-pot sonoelectrodeposition of poly (pyrrole)/Prussian blue nanocomposites: Effects of the ultrasound amplitude in the electrode interface and electrocatalytical properties. Electrochim. Acta 213, 822-830 (2016).

37. Tao, J.-Z. et al. Poly(m-phenylenediamine)-Prussian blue hybrid film formed by one-step electrochemical deposition for glucose biosensor. J. Electroanal. Chem. 689, 96-102 (2013).

38. Santoro, C., Babanova, S., Erable, B., Schuler, A. \& Atanassov, P. Bilirubin oxidase based enzymatic air-breathing cathode: Operation under pristine and contaminated conditions. Bioelectrochemistry 108, 1-7 (2016).

39. Kipf, E. et al. An air-breathing enzymatic cathode with extended lifetime by continuous laccase supply. Bioresour. Technol. 264, 306-310 (2018).

40. Bandapati, M. et al. Screening various pencil leads coated with MWCNT and PANI as enzymatic biofuel cell biocathode. Int. J. Hydrogen Energy 42, 27220-27229 (2017).

41. Reuillard, B. et al. One-year stability for a glucose/oxygen biofuel cell combined with $\mathrm{pH}$ reactivation of the laccase/carbon nanotube biocathode. Bioelectrochemistry 106, 73-76 (2015).

42. Chansaenpak, K. et al. Development of a sensitive self-powered glucose biosensor based on an enzymatic biofuel cell. Biosensors 11, 16. https://doi.org/10.3390/bios11010016 (2021).

43. Bollella, P., Lee, I., Blaauw, D. \& Katz, E. A Microelectronic sensor device powered by a small implantable biofuel cell. Chem. Phys. Chem. 21, 120-128 (2020).

44. Kashyap, D. et al. Fabrication of vertically aligned copper nanotubes as a novel electrode for enzymatic biofuel cells. Electrochim. Acta 167, 213-218 (2015).

45. Alsaoub, S. et al. Introducing pseudocapacitive bioelectrodes into a biofuel cell/biosupercapacitor hybrid device for optimized open circuit voltage. ChemElectroChem 6, 2080-2087 (2019).

46. Zhou, L. et al. Oriented immobilization of glucose oxidase on graphene oxide. Biochem. Eng. J. 69, 28-31 (2012).

\section{Acknowledgements}

This research has received funding from the Research Council of Lithuania (LMTLT), Project Agreement No. S-LU-20-11.

\section{Author contributions}

Conceptualization, A. K.-M.; Methodology, A. K.-M., A. P., and A. Ramanavicius.; Investigation, A. K. and A. P.; Validation, A. K.-M. and A. Ramanaviciene; Data curation and supervision, A. K.-M.; Software, A. P.; Resources, A. Ramanaviciene; Writing original draft, A. K.-M.; Writing - review \& editing, A. K.-M., A. P., A. Ramanavicius and A. Ramanaviciene; Funding acquisition, A. K.-M.

\section{Competing interests}

The authors declare no competing interests.

\section{Additional information}

Correspondence and requests for materials should be addressed to A.K.-M. or A.R.

Reprints and permissions information is available at www.nature.com/reprints.

Publisher's note Springer Nature remains neutral with regard to jurisdictional claims in published maps and institutional affiliations.

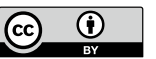

Open Access This article is licensed under a Creative Commons Attribution 4.0 International License, which permits use, sharing, adaptation, distribution and reproduction in any medium or format, as long as you give appropriate credit to the original author(s) and the source, provide a link to the Creative Commons licence, and indicate if changes were made. The images or other third party material in this article are included in the article's Creative Commons licence, unless indicated otherwise in a credit line to the material. If material is not included in the article's Creative Commons licence and your intended use is not permitted by statutory regulation or exceeds the permitted use, you will need to obtain permission directly from the copyright holder. To view a copy of this licence, visit http://creativecommons.org/licenses/by/4.0/.

(C) The Author(s) 2021 